\title{
A ASSISTÊNCIA DE ENFERMAGEM À MULHER EM PROCESSO DE ABORTAMENTO
}

\author{
Danielli Manheze Santana*, Rute Silva Dos Santos*, Bárbara Angélica Gómez Pérez** \\ Bacharelanda em Enfermagem da Escola Bahiana de Medicina e Saúde Pública. E-mail: dmanheze@hotmail.com, \\ rutesantos5@hotmail.com \\ Enfermeira Obstetra, Mestre em Enfermagem pela Universidade Federal da Bahia. Professora substituta da Universidade \\ Estadual da Bahia. Professora e Orientadora do Curso de Enfermagem da Escola Bahiana de Medicina e Saúde Pública.
}

\begin{abstract}
Resumo
Trata-se de uma pesquisa bibliográfica do tipo exploratória, que tem como objetivo descrever a assistência de Enfermagem à mulher em processo de abortamento. Ao decorrer dos anos, a problemática do abortamento vem sendo discutida a cerca da sua criminalização e esta discussão envolve diversos aspectos, como por exemplo, aspectos legais, culturais, religiosos, sociais e morais. Essa ilegalidade traz consequências negativas para as mulheres que praticam esse ato, inclusive risco a sua vida, pois acabam procurando meios clandestinos para a prática do abortamento. Diante dessa realidade, o abortamento vem aumentando o índice de Mortalidade Materna no Brasil e os profissionais de Enfermagem são os norteadores do cuidado, já que trabalham na linha de frente com a mulher em situação de abortamento. Nesta perspectiva, os resultados encontrados apontam que a humanização na assistência de enfermagem a mulher em processo de abortamento são fundamentais para o acolhimento e incentivam os relatos das mulheres em relação a seus sentimentos e necessidades.
\end{abstract}

Palavras- chave: Aborto; Assistência; Enfermagem

\section{ANURSING CARETO WOMANIN PROCESSOFABORTION}

\begin{abstract}
It is a literature of the exploratory type, which aims to describe the nursing care for women undergoing abortion. Along the years, the issue of abortion has been discussed about the criminalization and this discussion involves several aspects, suchas legal, cultural, religious, social and moral. This illegality has negative consequences for women who practice this act, including riskhis life, because just looking clandestine means for the practice of abortion. Given this reality, abortionis increasing the rate of maternal mortality in Brazil and nursing professional sare guiding care, already working on the front lines with the woman having an abortion. In this perspective, the results show that the humanization
\end{abstract}


of nursing care for women undergoing abortion are key to the host and encourage reports of women in relationto their feeling sand needs.

Kepwords: Abortion; Assistance; Nursing.

\section{INTRODUÇÃO}

A Organização Mundial de Saúde (OMS) ${ }^{(1)}$ define o abortamento como a interrupção da gravidez com o feto pesando menos de 500 gramas, ou com idade gestacional menor que 22 semanas. A palavra "aborto" refere-se ao produto eliminado no processo de abortamento.

Segundo o Ministério da Saúde,(2)em 2009, o tema Aborto manteve-se na lista de pesquisas nos últimos 20 anos. Dentre essas pesquisas, estão publicações de ensaios, artigos de opinião e peças argumentativas.

Atualmente, o assunto abortamento é uma matéria que deve ser tratada como um problema de Saúde Pública.Dessa maneira, deve-selevar em consideração que enfrentá-lo com seriedade significa entendê-lo como uma questão que requer cuidados em saúde e direitos humanos. (2)

A discussão do aborto envolve muitas questões, como por exemplo, aspectos legais, culturais, religiosos, sociais e morais. Verifica-se que a desigualdade de gênero, a desigualdade de acesso à educação, a falta de alternativas e recursos econômicos, fazem com que o abortamento atinja, principalmente, mulheres pobres e de áreas marginalizadas. ${ }^{(3)}$

O Abortamento é previsto no direito brasileiro como crime, com exceção de apenas duas situações: no caso de risco a vida da mulher ou de violência sexual. Ou seja, o Código Penal só permite o aborto quando não há outro meio de salvar a vida da gestante ou se a gravidez for resultado de estupro. No primeiro caso, o médico não precisa de autorização judicial. ${ }^{(2)}$ No entanto, a criminalização deste ato não tem diminuído a incidência do aborto, e sim contribuído para a prática desta ação em locais que causam agravos à saúde física, emocional e social da mulher.(4)

O Supremo Tribunal Federal (STF) decidiu, em 2011, autorizar a mulher a interromper a gravidez em casos de fetos anencéfalos, sem que a prática se configurasse aborto criminoso. A anencefalia é uma má-formação fetal congênita e irreversível conhecida como "ausência de cérebro", que leva à morte da criança poucas horas depois do parto. Em 65\% dos casos, segundo a Confederação $\mathrm{Na}$ cional dos Trabalhadores na Saúde (CNTS), a morte do feto é registrada ainda no útero.

O fato do aborto ainda ser ilegal no Brasil não impede que este seja praticado. Ao contrário, influencia e colabora para que essa prática seja exercida em clínicas clandestinas, que não oferecem nenhum tipo de segurança a paciente. ${ }^{(5)}$

A ilegalidade do aborto traz consequências negativas para as mulheres que o praticam, sendo na maioria das vezes mulheres pobres e que não possuem condições de obteremum serviço médico assistencial preparado para realizar um aborto seguro. ${ }^{(2)}$

Uma pesquisa do Ministério da Saúde realizada no Brasil no ano de 2005 mostra que o número de aborto chegou ao total de 1.054.243. Também revela que a ocorrência de aborto vem diminuindo desde 1992 até 2005, mas que ainda continua com um alto índice, pois para cada três nascidos vivos, existe um aborto induzido. ${ }^{(4)}$ 
A maioria dos estudos relacionados ao abortamento mostra que a faixa etária das mulheres que estão em processo de abortamento atinge a faixa etária entre 10 e 49 anos. Dentre esta faixa, há uma concentração grande de experiência por abortamento induzido na idade entre 17 e 19 anos. ${ }^{(2)}$

O Ministério da Saúde, ${ }^{(2)}$ em 2009, revelou que entre as mulheres que abortam $44,9 \%$ e $91,6 \%$ são católicas e mais de $70 \%$ vivem em uma relação estável ou segura. Evidencia também que essas mulheres possuem um nível de escolaridade diversificado e usavam algum tipo de método contraceptivo.

Estudos sobre conhecimento de métodos contraceptivos têm demonstrado que em geral as muIheres referem conhecer a maioria dos métodos disponíveis, principalmente pílula contraceptiva e condom masculino, embora, quando se avalia a qualidade da informação, se verifique uma menor proporção de conhecimento adequado. O conhecimento limitado dos métodos contraceptivos e a falta de programas nacionais de atenção à contracepção contribuem para o uso inadequado, abandono e falha do método, o que pode favorecer o abortamento provocado. ${ }^{(6)}$

O processo de abortamento representa uma das principais causas de morte materna no Brasil. Entre as gravidezes que terminaram em abortamento de 2000 a 2004, ocorreram 697 óbitos maternos. ${ }^{(7,4)}$

Morte materna é a morte de uma mulher durante a gravidez, no parto ou puerpério, independentemente da duração ou da localização da gravidez. Considera-se também como morte materna aquela que ocorre num período superior a 42 dias e inferior a um ano após o fim da gravidez, classificada, assim, como morte materna tardia. ${ }^{(7)}$

No Brasil, a subnotificação das mortes por aborto é um fator impactante nos estudos sobre este fenômeno, pois mascara a real ocorrência desse fato. As mulheres em situação de aborto incompleto ou com complicações, geralmente, sentem constrangimento e/ou medo em declarar seus abortamentos nos serviços de saúde, resultando em grande subnotificação do evento. ${ }^{(4)}$ Essa subno- tificação traz uma tendência de declínio nos resultados da taxa de óbito. Também mostra um decréscimo na idade de mulheres que foram a óbito por abortamento, principalmente no Nordeste ondea taxa de óbitos maternos por aborto é a principal causa de mortalidade materna. ${ }^{(7)}$

Definem-se como os norteadores do cuidado, o vinculo e a segurança oferecida pela equipe multiprofissional, principalmente, o enfermeiro que trabalha na linha de frente com a mulher em processo de abortamento. ${ }^{(8)}$

Cabe ao profissional que cuida da paciente em situação de abortamento, priorizar o bem-estar da mulher, sem julgar e opinar obre o motivo que a levou ao internamento. ${ }^{(2)}$

Com base nesses argumentos, e considerando o interesse no tema aborto, procurou-se descrever o modelo atual de Assistência de Enfermagem à MuIher em processo de abortamento, buscando tornar visível a maneira como essa assistência está sendo prestada no Serviço de Saúde.

Em vista disso, essa análise tem ointuito de responder às seguintes questões: Como a equipe de enfermagem presta assistência às mulheres que estão em processo de abortamento? Estão oferecendo acolhimento e orientação a essas mulheres?

Diante da necessidade de prestar uma atenção humanizada à mulher em processo de abortamento, e considerando essa assistência peça fundamental para reduzir o índice de morbimortalidade materna, este estudo tem como objetivo geral descrever a Assistência de Enfermagem á Mulher em Processo de Abortamento.

\section{METODOLOGIA}

O presente estudo caracteriza-se como uma revisão bibliográfica do tipo exploratória sobre o tema A Assistência de Enfermagem à Mulher em Processo de Abortamento. Trata-se de uma revisão de literatura, na qual foram analisados materiais referentes ao aborto e a assistência de enfermagem às mulheres que passam pelo processo do abortamento. 
Segundo Gil,(9) a revisão de literatura dedica-se à "contextualização teórica do problema e ao seu relacionamento com o que tem sido investigado a seu respeito." Sendo assim, essa revisão não é constituída apenas por referências e resumos, mas também por discussão crítica em contexto atual.

Para Oliveira, ${ }^{(10)}$ a revisão bibliográfica "é o levantamento da literatura relevante, já publicada na área, que serve de base à investigação do trabalho proposto". Não é apenas transcrever os dados, mas discutir ideias, fundamentos, sugestões dos autores selecionados, tendo como finalidade principal conhecer as diferentes formas de contribuição cientifica realizado sobre um determinado assunto.

A principal vantagem de um estudo bibliográfico, segundo Gil,(9) está no fato de permitir uma ampla cobertura sobre o assunto pesquisado. Mas, é importante conhecer as bases de dados de qualidade para que a pesquisa não repita informações equivocadas. Desta forma, o levantamento de dados foi realizado somente através de base de dados confiáveis, de reconhecimento internacional.

A coleta de dados foi realizada a partir de uma pesquisa no Portal Periódico Capes e na Biblioteca Virtual de Saúde, considerada uma das principais bases da área de saúde, a fim de identificar como está sendo prestada a Assistência de Enfermagem à Mulher em Situação de Abortamento.

No levantamento dos artigos, foram utilizados, a princípio, os Descritores em Ciências da Saúde (DeCS): Assistência, Enfermagem, Aborto e poste- riormente o Portal Periódico Capes e a Biblioteca Virtual de Saúde, e as bases de dados Lilacs, Medline e Scielo. Por ser um tema bastante discutido, foi encontrado um quantitativo muito grande de artigos, especificamente, 19.902 artigos na base de dados Medline, 425 na base de dados Lilacs e 3.065 na base de dados Scielo, todos localizados a partir da pesquisa com a palavra chave aborto, a qual foi refinada até chegar à quantidade de 30 artigos abordando o tema propostonesta pesquisa.

Após leitura dos resumos dos artigos encontrados, foram selecionados apenas sete que respondiam ao objetivo do estudo. Por acreditar que essa amostra não era suficiente para embasar o estudo, foram utilizados os Manuais do Ministério da Saúde, os quais serviram de base para a elaboração do artigo.

Foram selecionados artigos científicos publicados no período de 2003 a 2010 que se encontravam no idioma português e com a classificação $A_{1}$ e $A_{2}$, a partir da Web Qualis do Portal Capes.

Os critérios de exclusão empregados foram os artigos que não estavam na classificação anteriormente citada, não estavam no idioma português, e que não respondiam o objetivo do estudo.

Posteriormente, foi realizada uma leitura criteriosa dos trabalhos encontrados na íntegra, e, a partir dessa leitura, procedeu-se ao fichamento dos sete artigos selecionados e dispostos no Quadro 1, considerando o título do artigo, autores, revista, ano de publicação e classificação.

Quadro 1 - Artigos selecionados que se enquadram nas categorias de classificação para o estudo

\begin{tabular}{|c|c|c|c|c|}
\hline TíTULO DO ARTIGO & AUTORES & ANO & REVISTA & ClassificaçÃo \\
\hline $\begin{array}{l}\text { A mulher em situação de } \\
\text { abortamento: um enfoque } \\
\text { existencial. }\end{array}$ & $\begin{array}{l}\text { Boemer MR, Mariutti } \\
\text { MG. }\end{array}$ & 2003 & $\begin{array}{c}\text { RevEscEnferm } \\
\text { USP }\end{array}$ & A2 \\
\hline $\begin{array}{l}\text { O luto no processo de aborto } \\
\text { provocado. }\end{array}$ & $\begin{array}{c}\text { Gesteira SMA, Barbosa } \\
\text { VL, Endo PC. }\end{array}$ & 2006 & Acta Paul Enferm & A2 \\
\hline $\begin{array}{c}\text { O cuidado de enfermagem na } \\
\text { visão de mulheres em situação de } \\
\text { abortamento. }\end{array}$ & $\begin{array}{l}\text { Mariutti MG, Almeida } \\
\text { AM, Panobianco MS. }\end{array}$ & 2007 & $\begin{array}{l}\text { Rev Latino } \\
\text { Americana de } \\
\text { Enferm }\end{array}$ & Al \\
\hline
\end{tabular}




\begin{tabular}{|c|c|c|c|c|}
\hline TíTULO DO ARTIGO & AUTORES & ANO & REVISTA & ClassificaÇão \\
\hline \multicolumn{5}{|l|}{ Assistência à mulher em processo } \\
\hline $\begin{array}{c}\text { de abortamento provocado: } \\
\text { discurso de profissionais de } \\
\text { enfermagem }\end{array}$ & $\begin{array}{l}\text { Gesteira SMA, Diniz } \\
\text { NMF, Oliveira EM. }\end{array}$ & 2008 & Acta Paul Enferm & A2 \\
\hline $\begin{array}{c}\text { Ser cuidada por profissionais da } \\
\text { saúde: percepções e sentimentos } \\
\text { de mulheres que sofreram } \\
\text { abortamento. }\end{array}$ & $\begin{array}{l}\text { Bazotti KDV, Stumm } \\
\text { EMF, Kirchner R M. }\end{array}$ & 2009 & $\begin{array}{c}\text { Texto Contexto } \\
\text { Enferm }\end{array}$ & A2 \\
\hline $\begin{array}{l}\text { Reflexões sobre a assistência } \\
\text { de enfermagem prestada à } \\
\text { parturiente. }\end{array}$ & $\begin{array}{c}\text { Velho MB, Oliveira ME, } \\
\text { Santos EKA. }\end{array}$ & 2010 & REBEN & A2 \\
\hline $\begin{array}{c}\text { Mulheres hospitalizadas } \\
\text { por abortamento em uma } \\
\text { Maternidade Escola na Cidade do } \\
\text { Recife, Brasil. }\end{array}$ & $\begin{array}{l}\text { Ramos KS, Ferreira } \\
\text { ALCG, Souza Al. }\end{array}$ & 2010 & $\begin{array}{c}\text { RevEscEnferm } \\
\text { USP }\end{array}$ & A2 \\
\hline
\end{tabular}

A análise de dados, segundo Marconi e Lakatos, ${ }^{(11)}$ é a tentativa de evidenciar as relações existentes entre o fenômeno estudado e outros fatores. Essas relações podem ser estabelecidas em função de suas propriedades relacionadas de causa - efeito, produtor - produto, de correlações, de análise de conteúdo etc.

Assim, procedeu-se com as etapas do processo de análise de conteúdo temática, segundo Bardin: ${ }^{(12)}$

a) Pré-análise: leitura flutuante do material coletado; constituição do corpus da pesquisa;

b) Exploração do material: recorte em unidades de registro de contexto; codificação e classificação segundo categorias empíricas e teóricas;

c) Tratamento dos dados e interpretação: análise final dos dados obtidos.

Nesse sentido foi realizada uma análise crítica e minuciosa sobre a forma que esta sendo prestada a Assistência de Enfermagem à Mulher em Processo de Abortamento, enfatizando a importân- cia de uma humanização presente nesse tipo de assistência.

Não foi necessária a aprovação por um Comitê de Ética em Pesquisa por se tratar de uma pesquisa bibliográfica.

\section{RESULTADOS E DISCUSSÃO}

A partir da análise dos artigos foram construídas categorias, segundo a Teoria de Bardin, para uma abordagem significativa dos dados, sendo estas: Prática Legal x Prática Ilegal, Sentimentos, Humanização, Preconceito x Violência Institucional.

\section{PRÁTICA LEGAL $\mathrm{X}$ PRÁTICA ILEGAL}

Ao prestar atendimento às mulheres em processo de abortamento, os enfermeiros devem atuar com ética e responsabilidade, pois este processo envolve uma vida, uma história, uma escolha e o principal, envolve sentimentos. ${ }^{(8)}$ 
O código de ética diz que, durante o processo de assistência de enfermagem, os profissionais não devem deixar que suas crenças religiosas e filosóficas interfiram no atendimento. E com o sentido de não punir a mulher em abortamento, o governo criou a Comissão Tripartite. Essa comissão vem quebrar o silêncio que perdura por muito tempo a respeito do abortamento. A partir dessa ação, o governo admite o abortamento como uma questão de saúde pública, diante dos problemas e complexidades que envolvem a vida das mulheres em situação de abortamento. ${ }^{(13,14)}$

Pode-se observar que o governo, a partir de iniciativas e da criação da Norma Técnica Atenção Humanizada ao Abortamento, vem contribuindo para a melhoria do atendimento e prática de enfermagem sensibilizando os profissionais e contribuindo diretamente para uma assistência humanizada. E por se tratar de um problema de saúde pública, a exigência de atitudes éticas e responsáveis diante da situação do aborto tem aumentado.

É direito de toda pessoa a escolha, controle e poder sobre sua reprodutividade, livre de qualquer discriminação, repressão e violência. Os direitos reprodutivos fazem parte dos direitos humanos reconhecidos nos diversos tratados e convenções nacionais e internacionais. ${ }^{(6)}$

O sigilo na prática profissional é um dever legal e ético, sendo assim, o enfermeiro diante de um abortamento espontâneo ou provocado não deve comunicar o fato à autoridade judicial, policial, nem ao Ministério Público, exceto para proteção da usuária e com o seu consentimento. (3)

Diante dessa afirmativa, fica claro que o sigilo profissional é fundamental para uma assistência de qualidade a mulher em processo de abortamento, salvo para proteção da usuária e com seu consentimento, assegurando desta forma a integridade da mulher, sua moral e o respeito pelo seu direito reprodutivo.

No que diz respeito à prática legal, geralmente as mulheres em processo de abortamento esperam ser questionadas pelos profissionais, incluindo a equipe de Enfermagem. Estes questionamentos nem sempre tem uma abordagem ética e quando não são questionadas a respeito do motivo do abortamento ou da etiologia do mesmo, se sentem aliviadas. $^{(8)}$

Isso traz a reflexão os motivos pelos quais, muitas vezes, os enfermeiros questionam as mulheres em processo de abortamento de uma forma antiética e invasiva, culminando em um processo de constrangimento destas pacientes. Porém, o estigma do aborto e o preconceito podem contribuir para essa prática.

Os enfermeiros diante de uma situação de abortamento realizam, na maioria das vezes, apenas os procedimentos que abrangem as questões técnicas de tratamento da mulher. ${ }^{(5)}$

Os Médicos e equipe de Enfermagem estão preparados para lidar com procedimentos, técnicas, e planejamento de tratamento e não com a moral dos pacientes. ${ }^{(15)}$

É importante que a equipe multiprofissional chame a paciente pelo nome e não pelo procedimento a ser realizado, visando, assim, evitar constrangimentos. ${ }^{(8)}$

Muitas vezes os profissionais de Enfermagem discriminam as mulheres em processo de abortamento, quando priorizam prestar assistência a muIheres puerperais, parturientes e gestantes de alto risco. ${ }^{(16)}$

Sendo assim, fica claro que os profissionais estão preparados para realizar procedimentos, técnicas e planejamentos no tratamento do aborto, mas acabam por se fechar apenas a essas questões, deixando de lado a moral dos pacientes, o seu psicológico e sentimentos. Isso se reflete, em alguns casos, no momento em que há a priorização de atendimento ou execução de procedimentos em mulheres que, para alguns profissionais, não estão ali internadas porque "provocaram" o aborto. Dessa maneira, o serviçode assistência torna-sediscriminatório e influencia diretamente na qualidade da assistência prestada às mulheres que podem ter provocado o aborto. 


\section{SENTIMENTOS}

O profissional de saúde ao culpabilizar a mulher em processo de abortamento, referindo-se a este ato como crime, explicita a negação ao exercício do Direito Reprodutivo que vem sendo discutido e defendido pelo Movimento Feminista e Órgãos Nacionais e Internacionais, através de políticas públicas. ${ }^{(16)}$

Muitos enfermeiros estão despreparados e tem dificuldades em lidar com as mulheres em situação de abortamento e comseus sentimentos, o que ocasiona insegurança na assistência prestada, repercute diretamente na vivência dessas mulheres, e provoca medo e insegurança. ${ }^{(8)}$

Para muitas mulheres, o processo de abortamento é bastante desconfortável e doloroso, exigindo, desta forma, da equipe multiprofissional uma atenção qualificada para o controle da dor. Além disso, essas mulheres percebem e observam a capacidade dos profissionais em expressar suas impressões, pois o abortamento provoca percepções físicas e psicológicas, além de sentimentos diversos. ${ }^{(3,8)}$

Com relação ao sentimento dos profissionais e pacientes, pode-se entender que para muitos enfermeiros o aborto é um tema complicado de lidar e trabalhar, pois muitos o têm como crime e pecado. Isso provoca instabilidade emocional e preocupação nas pacientes em abortamento, já que estas estão ali expostas e recebendo uma assistência preconceituosa por parte destes profissionais.

A receptividade dos profissionais é primordial. Quando estes são receptivos, comunicativos e acolhedores, as mulheres que estão em processo de aborto percebem essas atitudes e isso lhes proporciona momentos de tranquilidade, conforto, sensação de bem-estar e segurança. ${ }^{(8)}$

Desta forma, percebe-se a importância do acoIhimento e comunicação entre o profissional e a paciente, tendo em vista que essas atitudes, além de interferirem diretamente nos sentimentos vivenciados porela, podem ser interpretadas de forma positiva ou negativa por cada paciente.

\section{HUMANIZACÃO}

Para se prestar uma assistência de qualidade e humanizada, deve-se considerar o acolhimento e orientações como elementos fundamentais. $\mathrm{O}$ acoIhimento envolve o ouvir, dar atenção, compreender e solidarizar-se com a mulher. E a orientação implica, de acordo com as diretrizes do Sistema Único de Saúde (SUS), no repasse de informações necessárias para o autocuidado e tomada de decisões, assim como toda e qualquer explicação que almeje sanar dúvidas sobre o assunto. ${ }^{(3)}$

A Enfermagem possui um papel importante no acolhimento, pois está presente desde a admissão da paciente, durante todos os procedimentos obstétricos e na recuperação clínica da mulher em fase de abortamento dentro do hospital.(3)

A partir destas afirmações do Ministério da Saúde, pode-se compreender que $o$ acolhimento e a orientação à mulher em processo de abortamento são elementos primordiais e que engloba toda a assistência de Enfermagem, ou seja, desde a admissão até a alta hospitalar essas ações podem interferir diretamente na recuperação e autoestima da mulher.

Apenas a valorização do indivíduo como um todo faz com que a ação humana seja reconhecida. Essa ação humana no cuidado é colocada em exercício no ato em que se transmite ou recebe o cuidado. ${ }^{(8)}$

O enfermeiro possui boa capacidade de comunicação interpessoal, consegue perceber e definir se a mulher esta sendo atendida em todas as suas necessidades. Contudo, esta comunicação não inclui somente o modo verbal, mas também o não verbal, como por exemplo, gestos, tom de voz, postura, olhares, entre outras atitudes dessa linguagem. ${ }^{(6)}$

Mesmo com todas as inconformidades da assistência de Enfermagem, o enfermeiro, mesmo que pouco, se preocupa com o estado emocional e físico das mulheres. No entanto, o médico realiza o procedimento de rotina, muitas vezes, sem enxergar a mulher com suas características emocionais. ${ }^{(8)}$

Dedicar mais tempo ao paciente não necessariamente resulta em um atendimento humanizado. É fundamental demonstrar segurança, ofertar palavras 
de conforto, carinho, conversar com a pessoa, darIhe atenção, deixar que se expresse e, até mesmo, que reclame. ${ }^{(6)}$

Desse modo, entende-se que a Assistência de Enfermagem prestada à mulher em processo de abortamento só é devidamente reconhecida quando o profissional reconhece que não basta apenas dedicar tempos prolongados junto ao paciente, compreende a importância do atendimento subjetivo e percebe o paciente de forma holística.

Os enfermeiros não devem esquecer que a muIher tem o direito de ter uma nova gestação algum tempo depois e que, para isso, também se faz necessário orientações sobre o planejamento de uma nova gestação. Essas orientações fazem com que o cuidado seja completo e envolva, por exemplo, a anticoncepção. ${ }^{(3)}$

Destarte, a equipe de enfermagem deve fornecer à mulher métodos de anticoncepção, lugares onde podem conseguir medicamentos e dispositivos gratuitamente e/ou comercializados. E o ideal é que a paciente já saia do ambiente hospitalar sabendo qual método utilizar e onde adquirir. (3)

Compreende-se, então, que o enfermeiro não deve se preocupar apenas com o tratamento hospitalar da paciente em processo de abortamento, pelo contrário, a mulher deve sair de alta do hospital com todas as orientações possíveis para evitar uma nova gravidez indesejada e suas consequências, como também, com o planejamento de uma nova gestação caso a mesma deseje.

O profissional de enfermagem deve adotar uma atitude terapêutica, desenvolvendo uma relação de empatia, com uma escuta ativa, sem julgamentos, criando uma comunicação sintonizada. (3)

\section{PRECONCEITO $\mathrm{X}$ VIOLÊNCIA INSTITUCIONAL}

O julgamento da sociedade, perante suas crenças interfere na assistência prestada à mulher em processo de abortamento. $O$ direito que a mulher tem sob sua sexualidade não tem nada haver com seu direito reprodutivo. Assim sendo, se a mulher tem uma vida sexual ativa, não necessariamente ela tem que estar casada e ter filhos. ${ }^{(17)}$

É importante que os enfermeiros reflitam sobre a ideia de que o sentimento é algo bastante pessoal. O fato da mulher não chorar e não manifestar seus sentimentos não significa que ela não está sofrendo pela situação que está passando. ${ }^{(17)}$

Alguns profissionais de enfermagem ao cuidar de mulheres em processo de abortamento, prestam uma assistência diferenciada a depender da etiologia do aborto, contudo, essa assistência deve ser igualitária a todas as mulheres, independente do seu poder aquisitivo e tipo de aborto. ${ }^{(17,8)}$

Enfermeiros que possuem uma vida religiosa consideram o abortamento como pecado, acreditam que ninguém tem o direito de tirar a vida do outro e que o aborto contraria os dogmas religiosos. Estes tipificam o aborto como crime e sabem que prestam uma assistência discriminatória. ${ }^{(16)}$

Mesmo quando o abortamento já passou pelo processo judicial e a mulher adquiriu o direito de abortar, a equipe de enfermagem encara o processo de abortamento como crime. ${ }^{(16)}$

É relevante a reflexão de que, a partir das crenças e entendimentos dos profissionais de enfermagem a respeito do abortamento, na maioria das vezes, surge uma assistência com julgamentos e criminalização. Assim, é importante o conhecimento, a conscientização e a sensibilização destes profissionais sobre os direitos da mulher, e o entendimento de que não se deve deixar as opiniões pessoais interferirem em sua assistência, e que isso pode acarretar em danos físicos e emocionais para estas mulheres.

A exposição do atendimento a mulher em situação de abortamento pela instituição, e o desrespeito moral, condiz com uma violência institucional. ${ }^{(16)}$

O Estado tem como dever manter profissionais que realizem abortamento dentro dos hospitais. Caso uma mulher venha a sofrer consequências de ordem física, psíquica ou moral por omissão de 
atendimento, poderá implicar em responsabilização pessoal e/ou institucional.(3)

É perceptível a relação de poder estabelecida entre os profissionais de saúde ea paciente, quando veem o corpo da mulher como um instrumento de trabalho, deixando de observar, muitas vezes, os aspectos psicológicos daquele momento. Essa visão subjetiva éde fundamental importância, frente à situação em que essa paciente está inserida.

Todo cidadão deve ser respeitado em suas particularidades, e esse respeito deve ocorrer desde algo simples, como uma informação, até os procedimentos a serem realizados. O profissional deve serético e valorizar os aspectos sociais, morais e espirituais que cada paciente possui.

\section{CONSIDERAÇÕES FINAIS}

Os resultados expostos permitem concluir que a criminalização do abortamento e sua clandestinidade no Brasil dificultam identificar suas reais dimensões e complexidade. Além desses fatores não diminuírem o número de abortamentos realizados, a sua prática insegura coloca em risco a vida das mulheres.

A penalização do aborto não protege a vida da mulher, já que o índice de mortalidade materna é maior que o índice de complicações decorrentes do aborto, o que resulta em, por exemplo, infecções e que por ventura são registradas como causa de morte, mascarando a realidade.

Embora se possa observar que os profissionais de saúde reconheçam os sentimentos dolorosos vivenciados pelas mulheres em processo de abortamento, fica evidente as atitudes discriminatórias, provavelmente influenciadas pela criminalização do aborto e suas leis restritivas vigentes no país.

Para uma modificação deste panorama, se faz importante uma qualificação dos profissionais que atuam diretamente na assistência dessas mulheres, fazendo com que os mesmos possam adquirir conhecimento e sensibilidade em relação ao abortamento e prestar assistência humanizada e segura a essas pacientes, contribuindo para a diminuição das sequelas físicas e emocionais, como, também sua recuperação pós-abortamento.

Portanto, a adoção de atitudes sem julgamentos, sem imposição de valores e a identificação das necessidades das mulheres em processo de abortamento são fundamentais para um bom acoIhimento e irá, ainda, dar incentivos para que as mulheres exponham seus sentimentos e falem de suas necessidades, além de proporcionar uma assistência integral e humanizada, e colaborar para a formação de profissionais voltados ao exercício do direito humano.

Sendo esse tema polêmico e de alto índice de mortalidade, é importante inseri-lo e aprofundá-lo na formação dos enfermeiros, pois é necessária a sensibilização, conhecimento e preparo dos discentes a respeito do assunto, permitindo que estes possam realizar uma assistência diferenciada e humanizada a essas mulheres.

\section{REFERÊNCIAS}

1. WHO. The prevention and management of unsafe abortion. Report of a Tehcnical Working Group. Geneva; 2005.

2. Brasil. Ministério da Saúde. Secretaria de Ciência, Tecnologia e Insumos Estratégicos. Departamento de Ciência e Tecnologia. 20 anos de pesquisas sobre aborto no Brasil. Brasília; 2009.

3. Brasil. Ministério da Saúde. Secretaria de Atenção à Saúde. Departamento de Ações Programáticas Estratégicas. Área Técnica de Saúde da Mulher. Atenção Humanizada ao Abortamento: norma técnica. Brasília; 2011.

4. Brasil. Ministério da Saúde. Secretaria de Atenção à Saúde. Departamento de Ações Programáticas Estratégicas. Área Técnica de Saúde da Mulher. Magnitude do Aborto no Brasil. Aspectos Epidemiológicos e SócioCulturais. Brasília; 2007.

5. Mariutti MG, Almeida AM, Panobianco MS. O cuidado de enfermagem na visão de mulheres em situação de abortamento. Rev. Esc. Enferm. 
USP. 2010; 44(3):605-1. Disponível em:<http:// www.scielo.br/pdf/reeusp/v44n3/08.pdf>

6. Silvia MJP. Qual o tempo do cuidado? Humanizando os cuidados de enfermagem. São Paulo: Edições Loyola; 2004.

7. Brasil. Ministério da Saúde. Secretaria de Atenção à Saúde. Departamento de Ações Programáticas Estratégicas. Área Técnica de Saúde da Mulher. Atenção Humanizada ao Abortamento: norma técnica. Brasília; 2010.

8. Bazotti KDV, Stumm EMF, Kirchner RM. Ser cuidada por profissionais da saúde: percepções e sentimentos de mulheres que sofreram abortamento. Texto \& contexto enferm. 2009; 18(1):147-54. Disponível em: <http://www.scielo. $\mathrm{br} / \mathrm{pdf} / \mathrm{tce} / \mathrm{vl} 8 \mathrm{nl} / \mathrm{vl} 8 \mathrm{nla18}$.pdf>.

9. Gil AC. Como elaborar projetos de pesquisa. $4^{\mathrm{a}}$ ed. São Paulo: Atlas; 2002.

1O. Oliveira SL de. Tratado de metodologia científica: projetos de pesquisa, TGI, TCC, monografias, dissertações e teses. Bessana MA, revisão. São Paulo: Pioneira Thompson Learning; 2002.

11. Marconi MA, Lakatos EM. Técnicas de pesquisa: planejamento e execução de pesquisas, amostragens e técnicas de pesquisas, elaboração, análise e interpretação de dados. $3^{a}$ ed. São Paulo: Atlas; 1996.
12. Bardin L. Análise de conteúdo. Lisboa: Ed.7O; 1994.

13. Conselho Federal de Enfermagem. Resolução COFEN-24O/200O, de 30 de agosto de 2000. Aprova o Código de Ética dos Profissionais de Enfermagem e dá outras providências. Disponível em: < http://www.cofen. gov.br/resoluo-cofen-2402000-revogada-pelaresolvo-cofen-3112007_4280.html>.

14. Rocha, MIB, Andalaft Neto JA. A questão do aborto: aspectos clínicos, legislativos e políticos. In: Berquó E, organizador. Sexo e vida: panorama da saúde reprodutiva no Brasil. Campinas: Editora da Unicamp; 2003. p. 257318.

15. Rezende, J. Obstetrícia. $8^{\mathrm{a}}$ ed. Rio de Janeiro: Guanabara Koogan; 2000.

16. Gesteira MAS, Diniz FMN, Oliveira FMN. Assistência à mulher em processo de abortamento provocado: discurso de profissionais de enfermagem. Acta paul enferm. 2008; 21(3):449-53. Disponível em: <http://www. scielo.br/pdf/ape/v2ln3/pt_l1.pdf>

17. Boemer MR, Mariutti MG. A mulher em situação de abortamento: um enfoque existencial. Rev. Esc. Enferm. USP. 2003; 37(2):59-71. 